\title{
Perfil de Sensibilidade aos Antibióticos na Infeção Urinária em Ambulatório no Distrito de Coimbra: Um Estudo Transversal
}

\section{Antimicrobial Susceptibility Patterns in Outpatient Urinary Tract Infection in the District of Coimbra, Portugal: A Cross-Sectional Study}

\author{
Carolina CURTO $₫, 1$, Inês ROSENDO ${ }^{1,2}$, Luiz SANTIAGO ${ }^{1,3,4}$ \\ Acta Med Port 2019 Sep;32(9):568-575 - https://doi.org/10.20344/amp.10862
}

\section{RESUMO}

Introdução: As infeções do trato urinário são muito frequentes na comunidade. É essencial conhecer o padrão de sensibilidade aos antibióticos para uma terapêutica empírica racional. O objetivo deste estudo é determinar a prevalência e o perfil de suscetibilidade aos antibióticos dos microrganismos implicados em infeções urinárias a nível dos cuidados primários de saúde, no distrito de Coimbra. Material e Métodos: Neste estudo observacional e transversal, analisámos 7134 uroculturas positivas de laboratórios de ambulatório do distrito de Coimbra, no período de um ano. Na maioria dos casos, a urocultura positiva foi definida por um limiar de $10^{5}$ unidades formadoras de colónias por mililitro e executada através do sistema automatizado VITEK® 2, da bioMérieux. Usámos estatística descritiva e inferencial para determinar a prevalência e a sensibilidade aos antibióticos dos microrganismos e averiguar a relação destas com o sexo e com a idade.

Resultados: Do total de uroculturas positivas, $83,4 \%$ pertencia ao sexo feminino e $41,0 \%$ pertencia à população acima dos 75 anos. A Escherichia coli foi o microrganismo mais frequente $(63,9 \%)$, mas a sua prevalência foi inferior $(p<0,001)$ no sexo masculino e acima dos 75 anos. A sua sensibilidade à fosfomicina e à nitrofurantoína foi superior a $95 \%$ e à ciprofloxacina e ao cotrimoxazol foi inferior a $80 \%$. As resistências foram mais frequentes $(p<0,001)$ no sexo masculino e nos mais idosos.

Discussão: A Escherichia coli foi o microrganismo mais frequente, verificando-se menores percentagens de resistência desta à fosfomicina e à nitrofurantoína. A sensibilidade aos antibióticos foi menor em idades mais avançadas e também no sexo masculino $(p<0,001)$, populações onde a antibioterapia empírica pode ter maior risco de insucesso.

Conclusão: Recomendamos a monitorização periódica do perfil de sensibilidade aos antibióticos, para eficaz informação aos médicos que têm de proceder a terapêutica empírica deste tipo de infeções, bem como a uniformização das técnicas de identificação das estirpes bacterianas e dos conjuntos de antibióticos a serem testados nos antibiogramas.

Palavras-chave: Antibacterianos/uso terapêutico; Farmacorresistência Bacteriana Múltipla; Infecções Urinárias; Portugal

\section{ABSTRACT}

Introduction: Urinary tract infections in the community setting are quite common. It is necessary to be aware of antibiotic susceptibility patterns in order to provide rational empirical therapy. The aim of this study is to determine the frequency and antimicrobial susceptibility of the strains responsible for urinary tract infections in primary health care, in the district of Coimbra, Portugal.

Material and Methods: In this observational and cross-sectional study, we analyzed 7134 positive urine cultures of outpatient laboratories in the district of Coimbra, over one year. In most cases, a positive culture was defined by a threshold of $10^{5}$ colony-forming units per milliliter and was conducted by the automated system VITEK® 2, by bioMérieux. We used descriptive and inferential statistics to determine the prevalence and antimicrobial susceptibility of bacteria and to ascertain whether there were differences associated with sex and age. Results: From the total of positive cultures, $83.4 \%$ pertained to females and $41.0 \%$ to individuals over 75 years old. Escherichia coli was the most frequent strain $(63.9 \%)$, although its prevalence was lower $(p<0.001)$ in males and individuals over 75 years old. Its susceptibility to fosfomycin and nitrofurantoin was higher than $95 \%$ and with ciprofloxacin and trimethoprim/sulfamethoxazole it was lower than $80 \%$. Resistances were more frequent $(p<0.001)$ in males and in the elderly.

Discussion: Escherichia coli was the most frequent strain, revealing less resistance to fosfomycin and nitrofurantoin. Antimicrobial susceptibility was lower in the elderly and in males, populations in whom empirical therapy may be less successful.

Conclusion: In order to improve clinical results, we recommend periodic surveillance of antimicrobial susceptibility, which could enable the provision of efficient information to clinicians, namely those who prescribe empirically for such infections, as well as standardization of identification methods of bacterial strains diagnosis and of the antibiotic kits to be tested.

Keywords: Drug Resistance, Multiple, Bacterial; Portugal; Urinary Tract Infections

\section{INTRODUÇÃO}

Atualmente, a resistência aos antibióticos representa um grave problema à escala mundial, que compromete o tratamento eficaz de muitas doenças e aumenta os custos em saúde. ${ }^{1-3}$ Vários fatores são implicados na emergência

1. Faculdade de Medicina. Universidade de Coimbra. Coimbra. Portugal.

2. Unidade de Saúde Familiar Coimbra Centro. Coimbra. Portugal.

3. Unidade de Saúde Familiar Topázio. Coimbra. Portugal.

4. Administração Regional de Saúde do Centro. Coimbra. Portugal.

$\bowtie$ Autor correspondente: Carolina Curto. cmlecurto@gmail.com

Recebido: 29 de maio de 2018 - Aceite: 16 de abril de 2019 | Copyright @ Ordem dos Médicos 2019 de estirpes resistentes, mas a pressão seletiva exercida pelo uso de antibióticos, particularmente o seu uso massivo e inapropriado, tem sido apontada como um dos que mais contribui para o problema. ${ }^{1-4}$ 
A resistência aos antibióticos é um fenómeno crescente,$^{5-7}$ com grandes variações geográficas, entre países e entre regiões de um mesmo país. ${ }^{8}$ Tendencialmente, as resistências são superiores no sul e leste da Europa, onde o consumo de antibióticos também é maior, ${ }^{3,4,8}$ comparativamente ao norte da Europa. ${ }^{5,9}$ Esta tendência verifica-se em Portugal, ${ }^{5,9}$ sendo que é a nível dos cuidados de saúde primários que ocorre o maior consumo destes medicamentos. ${ }^{3}$

As infeções do trato urinário (ITU) são um dos motivos mais frequentes de prescrição de antibióticos nos cuidados primários de saúde. ${ }^{10}$ Do ponto de vista anatómico, são divididas em ITU altas e baixas. Esta diferenciação é feita habitualmente com base na apresentação clínica. ${ }^{11}$ São ainda classificadas como complicadas ou não complicadas, dependendo da existência ou não de fatores que aumentem o risco de falência do tratamento ou de recorrência da infeção. ${ }^{11,12}$ As ITU são geralmente infeções bacterianas e monomicrobianas, sendo que os seus principais agentes etiológicos são Gram-negativos provenientes do cólon. ${ }^{8,11}$ A Escherichia coli (E. coli) é a responsável pela maioria dos casos, em todos os tipos de ITU, 5,6,11,13,14 embora a sua prevalência seja superior nas não complicadas. ${ }^{15}$ Outros microrganismos menos comuns são a Klebsiella pneumoniae (K. pneumoniae), o Proteus mirabilis ( $P$. mirabilis) e o Staphylococcus saprophyticus (S. saprophyticus)..$^{711,13,15}$ Mais raramente, as infeções são causadas por agentes como o Enterococcus faecalis (E. faecalis) e a Pseudomonas aeruginosa ( $P$. aeruginosa), principalmente implicados em ITU complicadas. ${ }^{11,15}$

A maioria das ITU ocorre na comunidade e a maioria são cistites não complicadas. ${ }^{8}$ Ainda que estas cistites tenham habitualmente um quadro clínico ligeiro, com baixo risco de complicações, ${ }^{8}$ está indicada a antibioterapia, por se associar a maior sucesso clínico e microbiológico, quando comparada com placebo. ${ }^{16}$ As recomendações terapêuticas nas ITU, e em particular nas ITU não complicadas, prevêem que esta antibioterapia seja empírica. 8,17,18

Nos últimos anos em Portugal, a $E$. coli tem mostrado elevadas resistências às quinolonas e ao cotrimoxazol, $, 4,13,14,17$ o que provavelmente se deve ao elevado consumo destes antibióticos nas últimas décadas. ${ }^{7,17}$ Já a fosfomicina e a nitrofurantoína, antibióticos recomendados como primeira linha no tratamento de cistites não complicadas, têm revelado um elevado perfil de sensibilidade por parte da E. coli. ${ }^{7,13}$

Existem poucas perspetivas de desenvolvimento de novas classes de antibióticos a curto prazo, pelo que é fundamental preservar a eficácia dos antibióticos disponíveis no arsenal terapêutico atual. ${ }^{1,2} \mathrm{~A}$ principal abordagem passa pela antibioterapia racional, que consiste em evitar a utilização desnecessária de antibióticos e em escolher adequadamente os princípios ativos e a posologia do tratamento. ${ }^{4,19}$ Este uso racional está dependente de uma boa vigilância epidemiológica, que permita o conhecimento dos padrões locais de resistência aos antibióticos ao longo do tempo. ${ }^{2}$

No caso das ITU, a monitorização periódica do perfil de sensibilidade aos antibióticos permitirá adequar as recomendações terapêuticas gerais à realidade local e, assim, otimizar o tratamento empírico. No entanto, em Portugal verifica-se uma escassez de estudos recentes na região centro, nomeadamente no distrito de Coimbra, no âmbito da resistência aos antibióticos nas ITU da comunidade.

O objetivo deste estudo é então avaliar a prevalência e o perfil de sensibilidade aos antibióticos dos principais agentes etiológicos implicados nas ITU da comunidade, no distrito de Coimbra.

\section{MATERIAL E MÉTODOS}

Realizou-se um estudo observacional e transversal, para o qual foi solicitado aos laboratórios do distrito de Coimbra o resultado das uroculturas positivas, com identificação da estirpe bacteriana e respetivo antibiograma, realizadas entre 1 de setembro de 2016 e 31 de agosto de 2017.

Para cada urocultura, pedia-se também o registo da idade e do sexo dos indivíduos. Os restantes dados seriam mantidos em anonimato e não foi solicitada a informação clínica que motivou a requisição da análise microbiológica da urina, por se saber que habitualmente tal não é parâmetro registado em laboratórios de ambulatório. Solicitou-se ainda a metodologia utilizada por cada laboratório quanto ao modo de cultura, número de unidades formadoras de colónias por mililitro (UFC/mL) e antibiograma.

A amostra compreendia 7134 uroculturas positivas de cinco laboratórios do distrito de Coimbra. Definimos urocultura positiva por um crescimento bacteriano superior ou igual a $10^{5} \mathrm{UFC} / \mathrm{mL}$, embora em alguns laboratórios também se tenha realizado o teste de sensibilidade aos antibióticos (TSA) perante contagens de $10^{4} \mathrm{UFC} / \mathrm{mL}$ ou $10^{3} \mathrm{UFC} / \mathrm{mL}$, casos que também foram incluídos na amostra.

Os microrganismos foram classificados como sensíveis, de sensibilidade intermédia ou resistentes a cada um dos antibióticos testados, segundo as normas padronizadas do Clinical and Laboratory Standards Institute (CLSI).

Relativamente aos métodos de identificação das estirpes bacterianas e de realização do TSA, a maioria dos laboratórios (81,5\% das uroculturas) utilizou o sistema automatizado VITEK® 2, da bioMérieux. Um laboratório (18,5\% das uroculturas) recorreu a métodos convencionais de identificação, nomeadamente a meios cromogénicos diferenciais, tendo usado sistemas automatizados apenas para os casos duvidosos. Nestes $18,5 \%$ dos casos, o TSA foi realizado pelo método de disco-difusão de Kirby-Bauer.

Determinou-se a frequência de uroculturas positivas por sexo e por grupo etário e a prevalência das estirpes bacterianas no total, em cada sexo e em cada grupo de idades. Apenas se selecionaram as estirpes mais frequentes, cada uma responsável por pelo menos $1 \%$ das uroculturas positivas, o que correspondeu a $95,3 \%$ da amostra.

O perfil de sensibilidade aos antibióticos foi analisado para os cinco microrganismos mais frequentes. Uma vez que a mesma estirpe não foi testada para o mesmo conjunto de antibióticos em todos os laboratórios, apenas se incluíram na análise os antibióticos considerados mais 
relevantes e testados em pelo menos $60 \%$ das amostras de cada uma das cinco estirpes mais frequentes.

Para o tratamento estatístico dos dados, utilizou-se o programa Statistical Package for the Social Sciences (SPSS), versão 23 para MacOS, onde se procedeu a uma análise descritiva e inferencial. Recorreu-se ao teste Quiquadrado para averiguar a existência de diferenças significativas entre os dois sexos e entre os diferentes grupos etários relativamente à prevalência dos microrganismos e aos perfis de sensibilidade aos antibióticos. O nível de significância estabelecido $(p)$ foi $p<0,05$ e a sensibilidade intermédia foi reclassificada em resistência.

Foi obtido parecer positivo da Comissão de Ética da ARS do Centro IP, que não obrigava a consentimento

Tabela 1 - Prevalência das estirpes bacterianas por sexo e total

\begin{tabular}{|c|c|c|c|c|}
\hline & $\begin{array}{c}\text { Sexo feminino } \\
\quad n=5951 \\
a=83,4 \%\end{array}$ & $\begin{array}{c}\text { Sexo masculino } \\
\qquad \begin{array}{c}n=1183 \\
a=16,6 \%\end{array}\end{array}$ & $\begin{array}{c}\text { Sexo Total } \\
n=7134\end{array}$ & \\
\hline Microrganismo & & $\mathrm{n}(\mathrm{b})$ & & $p$ \\
\hline Escherichia coli & $4037(67,8 \%)$ & $519(43,9 \%)$ & $4556(63,9 \%)$ & $<0,001$ \\
\hline Klebsiella pneumoniae & $590(9,9 \%)$ & $133(11,2 \%)$ & $723(10,1 \%)$ & $<0,001$ \\
\hline Proteus mirabilis & $327(5,5 \%)$ & $133(11,2 \%)$ & $460(6,4 \%)$ & $<0,001$ \\
\hline Esterococcus faecalis & $177(3,0 \%)$ & $59(5,0 \%)$ & $235(3,3 \%)$ & $<0,001$ \\
\hline Pseudomonas aeruginosa & $112(1,9 \%)$ & $100(8,5 \%)$ & $212(3,0 \%)$ & $<0,001$ \\
\hline Staphylococcus aureus & $80(1,3 \%)$ & $64(5,4 \%)$ & $144(2,0 \%)$ & \\
\hline Klebsiella oxytoca & $98(1,6 \%)$ & $40(3,4 \%)$ & $138(1,9 \%)$ & \\
\hline Streptococcus spp & $81(1,4 \%)$ & $9(0,8 \%)$ & $90(1,3 \%)$ & \\
\hline Enterobacter spp & $70(1,2 \%)$ & $14(1,2 \%)$ & $84(1,2 \%)$ & \\
\hline Citrobacter spp & $64(1,1 \%)$ & $18(1,5 \%)$ & $82(1,1 \%)$ & \\
\hline Morganella morganii & $58(1,0 \%)$ & $19(1,6 \%)$ & $77(1,1 \%)$ & \\
\hline Outros & $258(4,3 \%)$ & $75(6,3 \%)$ & $333(4,7 \%)$ & \\
\hline
\end{tabular}

$\mathrm{n}$ : frequência absoluta; a: frequência relativa de uroculturas positivas em cada sexo; b: frequência relativa dos microrganismos em cada sexo e total; $p$ : nível de significância

Tabela 2 - Prevalência das estirpes bacterianas por grupo etário

\begin{tabular}{|c|c|c|c|c|c|c|}
\hline & $\begin{array}{c}0-15 \text { anos } \\
n=107 \\
a=1,5 \%\end{array}$ & $\begin{array}{c}16-35 \text { anos } \\
n=732 \\
a=10,3 \%\end{array}$ & $\begin{array}{c}\mathbf{3 6}-\mathbf{5 5} \text { anos } \\
\mathrm{n}=1312 \\
a=18,4 \%\end{array}$ & $\begin{array}{c}56-75 \text { anos } \\
n=2054 \\
a=28,8 \%\end{array}$ & $\begin{array}{c}>75 \text { anos } \\
n=2923 \\
a=41,0 \%\end{array}$ & \\
\hline Microrganismo & & $n(b)$ & & & & $p$ \\
\hline E. coli & $62(57,9 \%)$ & $460(62,8 \%)$ & $954(72,7 \%)$ & $1400(68,2 \%)$ & $1677(57,4 \%)$ & $<0,001$ \\
\hline K. pneumoniae & $7(6,5 \%)$ & $57(7,8 \%)$ & $83(6,3 \%)$ & $184(9,0 \%)$ & $392(13,4 \%)$ & $<0,001$ \\
\hline P. mirabilis & $14(13,1 \%)$ & $47(6,4 \%)$ & $58(4,4 \%)$ & $123(6,0 \%)$ & $218(7,5 \%)$ & $<0,001$ \\
\hline E. faecalis & $3(2,8 \%)$ & $38(5,2 \%)$ & $47(3,6 \%)$ & $68(3,3 \%)$ & $79(2,7 \%)$ & $<0,001$ \\
\hline$P$. aeruginosa & $2(1,9 \%)$ & $4(0,5 \%)$ & $15(1,1 \%)$ & $64(3,1 \%)$ & $125(4,3 \%)$ & $<0,001$ \\
\hline S. aureus & $0(0,0 \%)$ & $25(3,4 \%)$ & $29(2,2 \%)$ & $34(1,7 \%)$ & $56(1,9 \%)$ & \\
\hline K. oxytoca & $3(2,8 \%)$ & $7(1,0 \%)$ & $10(0,8 \%)$ & $30(1,5 \%)$ & $88(3,0 \%)$ & \\
\hline Streptococcus spp & $2(1,9 \%)$ & $24(3,4 \%)$ & $29(2,2 \%)$ & $19(0,9 \%)$ & $16(0,5 \%)$ & \\
\hline Enterobacter spp & $0(0,0 \%)$ & $6(0,8 \%)$ & $13(1,0 \%)$ & $26(1,3 \%)$ & $39(1,3 \%)$ & \\
\hline Citrobacter spp & $2(1,9 \%)$ & $6(0,8 \%)$ & $19(1,4 \%)$ & $23(1,1 \%)$ & $32(1,1 \%)$ & \\
\hline M. morganii & $6(5,6 \%)$ & $0(0,0 \%)$ & $3(0,2 \%)$ & $20(1,0 \%)$ & $48(1,6 \%)$ & \\
\hline Outros & $6(5,6 \%)$ & $58(7,9 \%)$ & $52(4,0 \%)$ & $63(3,1 \%)$ & $153(5,2 \%)$ & \\
\hline
\end{tabular}

$\mathrm{n}$ : frequência absoluta; a: frequência relativa de uroculturas positivas em cada grupo etário; $b$ : frequência relativa dos microrganismos em cada grupo etário; $p$ : nível de significância 
A estirpe bacteriana mais frequentemente identificada foi a E. coli, em $63,9 \%$ dos casos, seguida da K. pneumoniae $(10,1 \%)$, P. mirabilis $(6,4 \%)$, E. faecalis $(3,3 \%)$ e $P$. aeruginosa $(3,0 \%)$ (Tabela 1). Estes microrganismos foram responsáveis por $86,7 \%$ da amostra.

Verificaram-se diferenças significativas $(p<0,001)$ entre sexos relativamente à distribuição das cinco principais estirpes bacterianas. A E. coli foi o microrganismo mais frequente em ambos os sexos, mas a sua prevalência foi maior no sexo feminino $(67,8 \%)$ do que no masculino (43,0\%). Já a $K$. pneumoniae, $P$. mirabilis, $E$. faecalis e $P$. aeruginosa foram mais prevalentes no sexo masculino (Tabela 1).

Também se encontraram diferenças significativas $(p<0,001)$ na distribuição dos principais microrganismos pelos vários grupos etários. Ainda que a $E$. coli tenha sido o microrganismo mais frequente em todos eles, foi menos prevalente nos extremos de idades, ou seja, acima dos 75 anos $(57,4 \%)$ e entre os 0 e os 15 anos $(57,9 \%)$. Pelo contrário, a maior prevalência de K. pneumoniae e $P$. aeruginosa ocorreu acima dos 75 anos (13,4\% e 4,3\%, respetivamente) e a maior frequência relativa de $P$. mirabilis ocorreu entre os 0 e os 15 anos $(13,1 \%$ ) (Tabela 2$)$.

Relativamente ao perfil de sensibilidade aos antibióticos, a $E$. coli foi sensível à fosfomicina em $96,7 \%$ dos casos e à nitrofurantoína em $97,9 \%$ dos casos. A sua sensibilidade à associação amoxicilina/ácido clavulânico foi de $81,0 \%$, à ciprofloxacina foi de $76,2 \%$ e ao cotrimoxazol foi de $76,7 \%$. As cefalosporinas testadas, cefuroxima acetil, ceftazidima, cefotaxima e cefepima, apresentaram sensibilidades de $82,2 \%, 88,4 \%, 88,7 \%$ e $89,0 \%$, respetivamente (Tabela 3 ).

A maior sensibilidade encontrada para a $K$. pneumoniae foi de $88,9 \%$ ao imipenem, sendo a sensibilidade aos restantes agentes testados inferior a $80 \%$. O P. mirabilis apresentou uma sensibilidade de $81,5 \%$ à amoxicilina/ácido clavulânico, $89,8 \%$ à cefuroxima acetil e superior a $90 \%$ às restantes cefalosporinas testadas. A sensibilidade do E. faecalis à ampicilina foi de $96,8 \%$ e à nitrofurantoína foi de $98,7 \%$. A P. aeruginosa foi sensível em $84,6 \%$ dos casos à amicacina, $84,0 \%$ à gentamicina, $81,6 \%$ à ceftazidima $\mathrm{e}$ $75,0 \%$ à cefepima (Tabela 3 ).

Os perfis de sensibilidade aos antibióticos diferiram significativamente $(p<0,001)$ entre o sexo feminino e o sexo masculino, tendo as resistências sido superiores no segundo grupo. Mais concretamente, no sexo masculino a sensibilidade geral à fosfomicina foi de $83,5 \%$ e à gentamicina foi de $80,5 \%$, sendo as restantes sensibilidades inferiores a $80 \%$. No sexo feminino, a sensibilidade geral à fosfomicina foi de $89,9 \%$ e à nitrofurantoína foi de $86,1 \%$ (Tabela 4). Considerando o caso específico da E. coli, o sexo masculino também apresentou resistências estatisticamente superiores $(p<0,001)$, embora em ambos os sexos a suscetibilidade à fosfomicina e à nitrofurantoína tenha sido superior a $90 \%$ e em ambos a suscetibilidade à ciprofloxacina e ao cotrimoxazol tenha sido inferior a 80\%. (Tabela 4).

Também se observaram diferenças significativas $(p<0,001)$ nos perfis de sensibilidade aos antibióticos entre os vários grupos etários. As maiores percentagens de suscetibilidade foram observadas no grupo entre os 16 e os 35 anos, exceto para a nitrofurantoína e para o cotrimoxazol, onde o pico de sensibilidade aos antibióticos ocorreu entre os 36 e os 55 anos. A partir destas faixas etárias, observou-se uma redução das percentagens de sensibilidade com o aumento da idade, sendo as maiores resistências observadas acima dos 75 anos. Mais especificamente, até aos 55 anos todos os antibióticos analisados mostraram percentagens de sensibilidade superiores a $80 \%$, mas

Tabela 3 - Perfil de sensibilidade aos antibióticos das principais estirpes bacterianas (\%)

\begin{tabular}{|c|c|c|c|c|c|}
\hline Antibiótico & E. coli & K. pneumoniae & P. mirabilis & E. faecalis & $P$. aeruginosa \\
\hline Amicacina & NR & NR & NR & NR & 84,6 \\
\hline Amoxicilina/Ácido clavulânico & 81,0 & 68,3 & 81,5 & NR & NR \\
\hline Ampicilina & 63,8 & 0,2 & 55,7 & 96,8 & NR \\
\hline Cefepima & 89,0 & 68,1 & 91,8 & NR & 75,0 \\
\hline Cefotaxima & 88,7 & 69,6 & 92,0 & NR & NR \\
\hline Ceftazidima & 88,4 & 66,9 & 91,0 & NR & 81,6 \\
\hline Cefuroxima acetil & 82,2 & 66,0 & 89,8 & NR & NR \\
\hline Ciprofloxacina & 76,2 & 60,3 & 61,5 & NR & 66,2 \\
\hline Cotrimoxazol & 76,7 & 69,6 & 74,3 & 24,1 & NR \\
\hline Ertapenem & NR & NR & 98,4 & NR & NR \\
\hline Fosfomicina & 96,7 & 74,1 & 72,0 & NR & NR \\
\hline Gestamicina & 91,6 & 78,1 & 81,4 & NR & 84,0 \\
\hline Imipenem & NR & 88,9 & 70,0 & 97,0 & 81,2 \\
\hline Levofloxacina & NR & NR & NR & 77,4 & NR \\
\hline Nitrofurantoína & 97,9 & 50,7 & 0,3 & 98,7 & NR \\
\hline Norfloxacina & NR & 57,0 & NR & NR & NR \\
\hline Piperacilina/Tazobactam & NR & NR & NR & NR & 69,0 \\
\hline
\end{tabular}

NR: não realizado ou realizado em menos de $60 \%$ dos casos 
Tabela 4 - Perfil de sensibilidade aos antibióticos por sexo (\%)

\begin{tabular}{|c|c|c|c|c|}
\hline Antibiótico & & Sexo feminino & Sexo masculino & $p$ \\
\hline \multirow{2}{*}{ Amoxicilina/Ácido clavulânico } & E. coli & 82,6 & 68,7 & $<0,001$ \\
\hline & Geral & 78,3 & 63,3 & $<0,001$ \\
\hline \multirow{2}{*}{ Cefuroxima acetil } & E. coli & 83,4 & 72,3 & $<0,001$ \\
\hline & Geral & 79,4 & 66,6 & $<0,001$ \\
\hline \multirow{2}{*}{ Ciprofloxacina } & E. coli & 78,9 & 54,3 & $<0,001$ \\
\hline & Geral & 76,2 & 53,4 & $<0,001$ \\
\hline \multirow{2}{*}{ Cotrimoxazol } & E. coli & 78,5 & 62,7 & $<0,001$ \\
\hline & Geral & 76,8 & 64,1 & $<0,001$ \\
\hline \multirow{2}{*}{ Fosfomicina } & E. coli & 97,0 & 94,0 & $<0,001$ \\
\hline & Geral & 89,9 & 83,5 & $<0,001$ \\
\hline \multirow{2}{*}{ Gestamicina } & E. coli & 92,6 & 84,3 & $<0,001$ \\
\hline & Geral & 89,7 & 80,5 & $<0,001$ \\
\hline \multirow{2}{*}{ Nitrofurantoína } & E. coli & 98,2 & 95,7 & $<0,001$ \\
\hline & Geral & 86,1 & 74,5 & $<0,001$ \\
\hline
\end{tabular}

Tabela 5 - Perfil de sensibilidade aos antibióticos por grupo etário (\%)

\begin{tabular}{|c|c|c|c|c|c|c|c|}
\hline Antibiótico & & $0-15$ anos & $16-35$ anos & $36-55$ anos & $56-75$ anos & $>75$ anos & $p$ \\
\hline \multirow{2}{*}{$\begin{array}{l}\text { Amoxicilina/ } \\
\text { Ácido clavulânico }\end{array}$} & E. coli & 90,2 & 89,1 & 87,7 & 81,7 & 74,1 & $<0,001$ \\
\hline & Geral & 85,4 & 87,7 & 85,4 & 77,5 & 68,1 & $<0,001$ \\
\hline \multirow{2}{*}{ Cefuroxima acetil } & E. coli & 94,1 & 89,5 & 90,3 & 83,7 & 73,7 & $<0,001$ \\
\hline & Geral & 85,7 & 89,6 & 88,7 & 79,5 & 68,1 & $<0,001$ \\
\hline \multirow{2}{*}{ Ciprofloxacina } & E. coli & 91,3 & 93,6 & 88,9 & 77,9 & 63,5 & $<0,001$ \\
\hline & Geral & 91,5 & 93,9 & 86,8 & 75,3 & 60,2 & $<0,001$ \\
\hline \multirow{2}{*}{ Cotrimoxazol } & E. coli & 82,0 & 87,4 & 86,5 & 77,0 & 68,0 & $<0,001$ \\
\hline & Geral & 84,6 & 85,5 & 85,9 & 75,7 & 66,1 & $<0,001$ \\
\hline \multirow{2}{*}{ Fosfomicina } & E. coli & 100,0 & 98,5 & 98,7 & 97,4 & 94,3 & $<0,001$ \\
\hline & Geral & 90,6 & 94,4 & 94,0 & 90,8 & 84,0 & $<0,001$ \\
\hline \multirow{2}{*}{ Gestamicina } & E. coli & 96,7 & 96,2 & 94,9 & 92,3 & 87,6 & $<0,001$ \\
\hline & Geral & 95,9 & 96,2 & 93,4 & 90,2 & 82,4 & $<0,001$ \\
\hline \multirow{2}{*}{ Nitrofurantoína } & E. coli & 100 & 99,8 & 99,1 & 98,1 & 96,5 & $<0,001$ \\
\hline & Geral & 82,6 & 89,6 & 91,7 & 86,5 & 78,0 & $<0,001$ \\
\hline
\end{tabular}

$\mathrm{n}$ : frequência absoluta; $\mathrm{a}$ : frequência relativa de uroculturas positivas em cada grupo etário; b: frequência relativa dos microrganismos em cada grupo etário; $p$ : nível de significância

acima dos 75 anos isto apenas se verificou para a fosfomicina e para a gentamicina (Tabela 5). Considerando o caso particular da E. coli, as resistências também foram estatisticamente superiores em idades mais avançadas, principalmente acima dos 75 anos, embora a fosfomicina e a nitrofurantoína tenham mantido sensibilidades superiores a $90 \%$ em todos os grupos etários (Tabela 5).

\section{DISCUSSÃO}

Neste estudo, a maior parte da amostra $(83,4 \%)$ foi proveniente do sexo feminino, o que está de acordo com vários outros trabalhos. ${ }^{6,13,14,20,21} \mathrm{~A}$ maior frequência de ITU nas mulheres é explicada pelo menor comprimento da uretra feminina, que facilita a ascensão de enterobactérias, e pela presença de substâncias antibacterianas no fluido prostático masculino. ${ }^{11,14}$
O facto de a maior frequência de uroculturas positivas $(41,0 \%)$ ter sido observada nas idades mais avançadas, acima dos 75 anos, é também concordante com outros estu$\operatorname{dos}^{6,13}$ e pode ser justificado pelo envelhecimento da população. Para além disso, o período pós-menopausa e outras alterações génito-urinárias e imunitárias poderão relacionar-se com uma maior prevalência de ITU nos mais idosos. ${ }^{7}$

A E. coli foi o microrganismo mais frequente $(63,9 \%)$, o que provavelmente está relacionado com os seus fatores de virulência. ${ }^{7,15}$ Os principais microrganismos a seguir à E. coli também foram semelhantes aos encontrados noutros estudos, ${ }^{13,18}$ à exceção do S. saprophyticus, o que poderá ser explicado por este ser um agente principalmente implicado em cistites não complicadas da mulher jovem. . $11,15^{-}$

A prevalência de $E$. coli foi significativamente maior no sexo feminino, enquanto a prevalência dos outros 
microrganismos mais frequentes foi maior no sexo masculino. Estas diferenças poderão estar relacionadas com o facto de nos homens as ITU serem habitualmente complicadas, ${ }^{11,12}$ devido a fatores como obstrução do trato urinário ou instrumentação prévia do mesmo. ${ }^{15}$

A menor prevalência de $E$. coli foi observada no grupo acima dos 75 anos $(57,4 \%)$, onde se registou a maior frequência de $K$. pneumoniae $(13,4 \%)$ e $P$. aeruginosa $(4,3 \%)$. Este facto poderá estar associado a uma maior frequência de infeções complicadas em idades mais avançadas, de hospitalizações e residência em lares, potenciando infeções por agentes menos comuns na comunidade.$^{6,7} \mathrm{O}$ grupo etário abaixo dos 16 anos foi o segundo com menor prevalência de $E$. coli $(57,9 \%)$ e foi onde se observou a maior frequência de $P$. mirabilis $(13,1 \%)$. Esta ocorrência pode ser explicada pelo facto de nas crianças a ocorrência de ITU se relacionar frequentemente com a presença de anomalias congénitas do trato urinário, associadas a infeções complicadas. ${ }^{15,20}$

Linhares et al, num estudo realizado no distrito de Aveiro, também detetou diferenças na prevalência dos microrganismos entre os dois sexos, nomeadamente na prevalência de $E$. coli, mais frequente no sexo feminino, e de $P$. aeruginosa, mais frequente no sexo masculino. Identificou ainda diferenças entre os grupos etários, semeIhantes às aqui detetadas, mas apenas quando os dois sexos foram discriminados. ${ }^{6}$

A fosfomicina e a nitrofurantoína são recomendadas pela Direção-Geral da Saúde (DGS) como antibióticos de primeira linha no tratamento de cistites não complicadas ${ }^{17}$ e, neste estudo, as percentagens de sensibilidade da E. coli a estes antibióticos foram superiores a $95 \%$. A fosfomicina tem boas propriedades farmacocinéticas e farmacodinâmicas, de tal modo que uma toma única deste fármaco seja capaz de eliminar o agente patogénico, reduzindo o risco de seleção de estirpes multirresistentes. ${ }^{7}$ Relativamente à nitrofurantoína, o seu uso é por vezes visto com alguma apreensão na prática clínica, devido à necessidade de um tratamento prolongado, com várias administrações diárias, e ao receio de possível toxicidade e menor eficácia perante diminuição da função renal. ${ }^{18,22} \mathrm{O}$ facto de não ser muito utilizada poderá justificar a manutenção de um elevado perfil de sensibilidade por parte da E. coli. ${ }^{18}$ Há que realçar que estes antibióticos não apresentam uma boa penetração parenquimatosa, pelo que não são adequados para o tratamento de pielonefrites ou de infeções urinárias com envolvimento prostático. ${ }^{13,20}$

A sensibilidade da $E$. coli à associação amoxicilina/ácido clavulânico foi de $81,0 \%$, o que também parece concordar com o facto de só estar indicada em cistites não complicadas na impossibilidade de se utilizarem os antibióticos anteriores. ${ }^{17}$

As elevadas taxas de resistência ao cotrimoxazol e às quinolonas em Portugal referidas noutros estudos semeIhantes ${ }^{13,14}$ também se observaram aqui, ainda que o consumo de quinolonas na comunidade tenha vindo a diminuir nos últimos anos. ${ }^{4}$ No entanto, nos grupos etários até aos
55 anos essa asserção não se verificou, pelo que fatores relacionados com a idade e com a maior frequência de hospitalizações poderão estar na origem das maiores resistências. ${ }^{23}$

As diferenças encontradas nos perfis de sensibilidade aos antibióticos entre os grupos etários e entre os dois sexos justificam uma maior precaução na terapêutica de ITU em idosos e no sexo masculino, populações onde as resistências foram mais frequentes. Se considerarmos apenas a $E$. coli, apesar das diferenças observadas, as sensibilidades à fosfomicina e à nitrofurantoína mantiveram-se elevadas em ambos os sexos e em todos os grupos etários. No entanto, a prevalência de $E$. coli foi significativamente inferior no sexo masculino e acima dos 75 anos. O sexo masculino correspondeu a uma pequena parte da amostra, mas o grupo etário acima dos 75 anos foi o que registou a maior frequência de uroculturas positivas, o que torna essencial uma visão geral dos perfis de sensibilidade aos antibióticos, e não apenas a visão da $E$. coli. De facto, olhando para as percentagens gerais de sensibilidade por sexo e por grupo etário, acima dos 75 anos e no sexo masculino, estas raramente foram superiores a $80 \%$.

As maiores resistências nos mais idosos poderão estar relacionadas com o aumento das hospitalizações e com o domicílio em lares, ambientes onde as resistências parecem ser maiores do que na comunidade. ${ }^{6,24}$ Linhares et al também detetou maiores resistências com o aumento da idade e no sexo masculino. ${ }^{6}$

As ITU mais comuns são as cistites não complicadas, pelo que é de grande utilidade o conhecimento da epidemiologia e dos padrões de resistência aos antibióticos dos seus agentes etiológicos. No entanto, a análise bacteriológica da urina não é habitualmente obrigatória para o diagnóstico e tratamento de cistites não complicadas, sendo muitas vezes suficientes as características clínicas e a realização do teste à urina com tira reagente. ${ }^{10,12}$ Por um lado, isto implica que exista escassez de informação. ${ }^{12,25}$ Por outro lado, torna admissível que os resultados deste estudo e de outros semelhantes sobrestimem os padrões de resistência locais, devido a um desequilíbrio da amostra, que provavelmente inclui um número de cistites não complicadas inferior ao real. ${ }^{10,11}$ Esta situação poderá também enviesar a prevalência de ITU na comunidade, sendo que não podemos concluir que estas sejam mais frequentes em idosos apenas baseado no facto de nesta população a percentagem da amostra ter sido maior.

Passadouro et al, num trabalho na região do Pinhal Litoral que também se baseou apenas em uroculturas positivas, encontrou resistências semelhantes às observadas neste trabalho. ${ }^{13}$ No entanto, Kahlmeter et al, num estudo multinacional que só incluiu uroculturas de mulheres com cistites não complicadas, revelou resistências mais baixas em Portugal do que as encontradas aqui. ${ }^{5}$ Há que realçar que este último estudo tem já alguns anos, o que também torna difícil a comparação.

O presente estudo apresenta como limitação o facto de se basear apenas no resultado de uroculturas, sem ter em 
conta o tipo de ITU, o motivo clínico do pedido e a patologia da pessoa de onde a urina foi colhida. Não é também um estudo aleatório mas sim epidemiológico, no qual se tentou ter o mais lato ambiente geográfico e o maior número de casos, mas estando limitado aos laboratórios respondentes. No entanto, o tamanho da amostra, 7134 casos, é por si só fator de resultados robustos.

Outra limitação deste trabalho prende-se com a falta de uniformização de critérios e de métodos entre os laboratórios. A definição de urocultura positiva é variável na literatura, sendo-o também entre diferentes laboratórios. Classicamente, baseava-se num crescimento bacteriano superior ou igual a $10^{5} \mathrm{UFC} / \mathrm{mL} .{ }^{11}$ No entanto, este limiar estaria associado a um grande número de falsos negativos, pelo que se têm considerado valores mais baixos, dependendo do método de colheita e da apresentação clínica. ${ }^{8,11}$ Porém, os laboratórios que procedem à análise da urina nem sempre têm acesso a esses dados e estes valores não estão padronizados entre todos os laboratórios, o que poderá levar a diferenças nos resultados.

Também os métodos de identificação das estirpes bacterianas e de realização do TSA podem não estar padronizados. Mesmo os laboratórios que utilizaram o mesmo método, nem sempre testaram os mesmos antibióticos, o que poderá dificultar a interpretação dos resultados e a sua comparação. ${ }^{27}$ Para além disso, os antibióticos incluídos no TSA nem sempre foram os mais úteis para a prática clínica, na medida em que se testaram vários antibióticos pouco relevantes e não foram testados antibióticos cujo perfil de sensibilidade seria útil de conhecer. Um exemplo é a ceftriaxona, recomendada pela DGS no tratamento de pielonefrites ligeiras a moderadas, ${ }^{17}$ mas testado apenas numa minoria dos casos, razão pela qual não foi incluído nos resultados.

Apesar das limitações metodológicas apresentadas, principalmente a ausência de informação clínica, acredita-se que os dados encontrados neste estudo poderão ser úteis à orientação da terapêutica empírica de ITU da comunidade no distrito de Coimbra, onde não existiam dados prévios. Também poderão ajudar na sensibilização dos clínicos para a necessidade de uma prescrição racional da antibioterapia.

Um ponto forte deste trabalho é o facto de ter salientado as limitações inerentes à eventual falta de padronização dos métodos de análise bacteriológica da urina e de realização do TSA. Esta é uma questão pouco abordada noutros estudos e que poderá ajudar a reconhecer a necessidade de se uniformizarem os métodos e de serem testados conjuntos de antibióticos mais relevantes para determinada situação clínica.

Deste conhecimento epidemiológico e de sensibilidade bacteriana a ser regularmente realizado, poderão advir recomendações atempadas para o mais correto uso de antibióticos de forma empírica na suspeita de ITU pelo que, no futuro, será importante manter a vigilância epidemiológica e acompanhar a evolução temporal do padrão de resistências aos antibióticos no distrito de Coimbra. Salienta-se a relevância do uso futuro de métodos de monitorização mais adequados, que tenham em conta o tipo de ITU e outros possíveis fatores de risco para resistência aos antibióticos, como a antibioterapia prévia, a hospitalização recente ou a presença de ITU recorrentes. . $3,25,27^{23}$

\section{CONCLUSÃO}

Neste estudo, as menores percentagens de resistência da $E$. coli ocorreram para a fosfomicina e para a nitrofurantoína, agentes recomendados como primeira linha no tratamento de cistites não complicadas, que são as ITU mais frequentes na comunidade. A associação amoxicilina/ ácido clavulânico parece ser uma alternativa menos vantajosa para o tratamento desta entidade. A ciprofloxacina e o cotrimoxazol mantêm elevadas resistências por parte da E. coli, embora nos grupos etários mais jovens tal não se tenha verificado.

A prevalência de $E$. coli e a sensibilidade aos antibióticos foram menores em idades mais avançadas e também no sexo masculino $(p<0,001)$, populações onde a antibioterapia empírica poderá ter maior risco de falhar e onde a abordagem das infeções urinárias deverá ser mais cautelosa.

As resistências aos antibióticos são uma ameaça ao progresso conseguido na medicina nas últimas décadas e a monitorização periódica dos padrões locais de sensibilidade aos antibióticos é uma medida fundamental na abordagem a este problema. Reforça-se a importância de que sejam seguidas metodologias cada vez mais adequadas, para que o conhecimento do padrão de resistências seja o mais preciso possível e de que esse conhecimento seja transmitido de forma eficaz aos médicos que têm de proceder a terapêutica de ITU de forma empírica.

\section{AGRADECIMENTOS}

Os autores gostariam de agradecer aos laboratórios de análises clínicas de Coimbra que colaboraram neste estudo e aos seus respetivos diretores técnicos: laboratório Uália e João Pego; laboratório Beatriz Godinho, Maria Beatriz Santos e Filipa Paredes; laboratório Coimbralab e Helena Leal; laboratório Aeminium.

\section{PROTECÇÃO DE PESSOAS E ANIMAIS}

Os autores declaram que os procedimentos seguidos estavam de acordo com os regulamentos estabelecidos pelos responsáveis da Comissão de Investigação Clínica e Ética e de acordo com a Declaração de Helsínquia da Associação Médica Mundial.

\section{CONFIDENCIALIDADE DOS DADOS}

Os autores declaram ter seguido os protocolos do seu centro de trabalho acerca da publicação de dados.

\section{CONFLITOS DE INTERESSE}

Os autores declaram não ter conflitos de interesses relacionados com o presente trabalho. 


\section{FONTES DE FINANCIAMENTO}

Este trabalho não recebeu qualquer tipo de suporte financeiro de nenhuma entidade no domínio público ou privado.

\section{REFERÊNCIAS}

1. Aryee A, Price N. Antimicrobial stewardship - can we afford to do without it? Br J Clin Pharmacol. 2015;79:173-81.

2. World Health Organization. Global action plan on antimicrobial resistance. Geneva: World Health Organization; 2015. [consultado 2018 fev 09]. Disponível em http://www.wpro.who.int/entity/drug_resistance/ resources/global_action_plan_eng.pdf.

3. Ramalhinho I, Ribeirinho M, Vieira I, Cabrira J. A evolução do consumo de antibióticos em ambulatório em Portugal continental 2000-2009. Acta Med Port. 2012;25:20-8.

4. Direção-Geral da Saúde. Programa de prevenção e controlo de infeções e de resistência aos antimicrobianos 2017. Lisboa: Direção-Geral da Saúde; 2017. [consultado 2018 fev 09]. Disponível em https://www.sns. gov.pt/wp-content/uploads/2017/12/DGS PCIRA V8.pdf.

5. Kahlmeter G, Poulsen HO. Antimicrobial susceptibility of Escherichia coli from community-acquired urinary tract infections in Europe: the ECO.SENS study revisited. Int J Antimicrob Agents. 2012;39:45-51.

6. Linhares I, Raposo T, Rodrigues A, Almeida A. Frequency and antimicrobial resistance patterns of bacteria implicated in community urinary tract infections: a ten-year surveillance study (2000-2009). BMC Infect Dis. 2013;13:19.

7. Narciso A, Fonseca F, Cerqueira SA, Duarte A. Susceptibilidade aos antibióticos de bactérias responsáveis por cistites não complicadas: estudo comparativo dos isolados de 2008 e 2010. Acta Urol. 2011;1:16-21.

8. Rolo F, Parada B, Moreira P. Cistite não complicada na mulher. Guia multidisciplinar reconhecido pela Associação Portuguesa de Urologia. 2008. [consultado 2018 fev 09]. Disponível em: http://www. apurologia.pt/ pdfs/Guia-cistite.pdf.

9. European Centre for Disease Prevention and Control. Antimicrobial resistance surveillance in Europe. Annual report of the European Antimicrobial Resistance Surveillance Network (EARS-Net). 2016. [consultado 2018 fev 09]. Disponível em: https:// www.ecdc.europa.eu/ sites/portal/files/documents/AMR-surveillance-Europe-2016.pdf.

10. Chin TL, McNulty C, Beck C, MacGowan A. Antimicrobial resistance surveillance in urinary tract infections in primary care. J Antimicrob Chemother. 2016;71:2723-8.

11. Wang A, Nizran P, Malone MA, Riley T. Urinary tract infections. Prim Care. 2013;40:687-706.

12. Bonkat $G$, Pickard $R$, Bartoletti $R$, Cai $T$, Bruyère $F$, Geerlings $S E$, et al. European Association of Urology Guidelines on Urological Infections. European Association of Urology; 2018. [consultado 2018 fev 09]. Disponível em: http://uroweb.org/guideline/urological-infections/.

13. Passadouro R, Fonseca R, Figueiredo F, Lopes A, Fernandes C. Avaliação do perfil de sensibilidade aos antibióticos na infeção urinária da comunidade. Acta Med Port. 2014;27:737-42.

14. Martins F, Vitorino J, Abreu A. Avaliação do perfil de susceptibilidade aos antimicrobianos de microrganismos isolados em urinas na região do Vale do Sousa e Tâmega. Acta Med Port. 2010;23:641-6.
15. Kasper DL, Fauci AS, Hauser SL, Longo DL, Jameson JL, Loscalzo J. Harrison's principles of internal medicine. $19^{a}$ ed. Nova lorque: McGraw Hill Education; 2015

16. Falagas ME, Kotsantis IK, Vouloumanou EK, Rafailidis PI. Antibiotics versus placebo in the treatment of women with uncomplicated cystitis: a meta-analysis of randomized controlled trials. J Infect. 2009;58:91-102.

17. Direção-Geral daSaúde. Norman ${ }^{\circ} 015 / 2011$ de 30/08/2011 - Terapêutica de infeções do aparelho urinário (comunidade). Lisboa: Direcção-Geral de Saúde; 2011:015/2011. [consultado 2018 fev 09]. Disponível em: https://www.dgs.pt/directrizes-da-dgs/normas-e-circulares-normativas. aspx.

18. Betrán A, Cortés AM, López C. Evaluación de la resistencia antibiótica de Escherichia coli en infecciones urinarias adquiridas en la comunidad del Sector Sanitario de Barbastro (Huesca). Rev Esp Quimioter. 2015;28:263-6.

19. Dolk FC, Pouwels KB, Smith DR, Robotham JV, Smieszek T. Antibiotics in primary care in England: which antibiotics are prescribed and for which conditions? J Antimicrob Chemother. 2018;73:S2-10.

20. McGregor JC, Elman MR, Bearden DT, Smith DH. Sex- and age-specific trends in antibiotic resistance patterns of Escherichia coli urinary isolates from outpatients. BMC Fam Pract. 2013;14:25.

21. Malmartel A, Ghasarossian C. Epidemiology of urinary tract infections, bacterial species and resistances in primary care in France. Eur J Clin Microbiol Infect Dis. 2016;35:447-51.

22. Cunha BA, Cunha CB, Lam B, Giuga J, Chin J, Zafonte VF, et al. Nitrofurantoin safety and effectiveness in treating acute uncomplicated cystitis (AUC) in hospitalized adults with renal insufficiency: antibiotic stewardship implications. Eur J Clin Microbiol Infect Dis. 2017;36:1213-6.

23. Kratochwill L, Powers M, McGraw MA, King L, O'Neill JM, Venkat A Factors associated with ciprofloxacin-resistant Escherichia coli urinary tract infections in discharged ED patients. Am J Emerg Med. 2015; $33: 1473-6$

24. Fleming A, Barry L, Byrne S, Prentice M. Antimicrobial susceptibility of long term care facility and general practice urine samples in patients 65 years and older: an observational study. Eur J Public Health. 2017;27:307-12

25. Rossignol L, Maugat S, Blake A, Vaux S, Heym B, Le Strat Y, et al. Risk factors for resistance in urinary tract infections in women in general practice: a cross-sectional survey. J Infect. 2015;71:302-11.

26. World Health Organization. Global strategy for containment of antimicrobial resistance. Geneva: World Health Organization; 2001. [consultado 2018 fev 09]. Disponível em: http://www.who.int/ drugresistance/WHO_Global_Strategy_English.pdf.

27. Hertz FB, Schønning K, Rasmussen SC, Littauer P, Knudsen JD, Løbner-Olesen A, et al. Epidemiological factors associated with ESBLand non ESBL-producing $\mathrm{E}$. coli causing urinary tract infection in general practice. Infect Dis. 2016;48:241-5. 